\title{
Influência do puerpério e da fase pós-puerperal no lipidograma de vacas da raça Holandesa criadas no Estado de São Paulo
}

Regiane Machado de SOUZA $^{1}$

Eduardo Harry BIRGEL JUNIOR ${ }^{1}$

\section{Correspondência para:}

Eduardo Harry Birgel Junior, Departamento de Clínica Médica da Faculdade de Medicina Veterinária eZootecnia/USP, Av. Prof. Orlando Marques de Paiva, 87 05508-900, Cidade Universitária São Paulo-SP, ehbirgel@usp.br

Recebido para publicação: 09/01/2007 Aprovado para publicação: 27/11/2008

\author{
1 - Departamento de Clínica Médica da Faculdade de Medicina Veterinária e \\ Zootecnia da Universidade de São Paulo, São Paulo-SP
}

\section{Resumo}

Palavras-chave:

Bovinos.

Lipidograma.

Com o objetivo de avaliar a influência do puerpério fisiológico e da fase pós-puerperal no lipidograma de vacas sadias foram colhidas 104 amostras de sangue por punção da veia coccígea de fêmeas da raça Puerpério. Holandesa. pela determinação dos teores séricos de colesterol, triglicérides, ácidos graxos não esterificados, beta-hidroxibutirato, e teores plasmáticos de glicose. Observou-se que os teores séricos de colesterol aumentaram gradativamente, enquanto os teores de ácidos graxos não esterificados diminuíram gradativamente com a evolução do puerpério. $\mathrm{Na}$ fase pós-puerperal (mais de 45 dias pós-parto) ocorreu a estabilização dos valores de colesterol e de ácidos graxos não esterificados.

\section{Introdução}

Apesar da evolução ocorrida nas últimas décadas nos conhecimentos relacionados à bioquímica clínica veterinária, constatou-se que o número de pesquisas com objetivo de estabelecer valores de referência para diversos constituintes do soro sangüíneo para as condições brasileiras de manejo, alimentação e clima são, ainda, insuficientes. Para alguns destes constituintes, como aqueles que fazem parte da avaliação do lipidograma dos bovinos, a revisão de literatura mostra a quase inexistente preocupação dos pesquisadores brasileiros no estabelecimento de valores de referência, pois exceção à pesquisa realizada por Costa ${ }^{1}$, na qual o referido autor avaliou a influência da gestação e do puerpério nos valores de colesterol e triglicérides, as demais pesquisas ${ }^{2,3,4}$ não tinham como intuito estabelecer valores de referência ou de avaliar fatores fisiológicos que pudessem interferir nos valores de normalidade do lipidograma.

Diante da necessidade da realização de estudos para estabelecer valores de referência do lipidograma e para avaliar a influência de diversos fatores nos seus valores decidiu-se pela elaboração da presente pesquisa, cujo objetivo é estudar a influência do puerpério e da fase pós-puerperal no lipidograma, de vacas holandesas criadas no Estado de São Paulo, sendo tal avaliação realizada por meio da determinação dos teores séricos de colesterol, triglicérides, ácidos graxos não esterificados (AGNE), beta-hidroxibutirato e dos teores plasmáticos de glicose.

\section{Material e Método}

Foram colhidas 104 amostras de soro e plasma sangüíneo de bovinos da raça Holandesa, criados em 14 propriedades paulistas produtoras de leite do tipo $\mathrm{B}$, nas quais a produção diária de leite do rebanho variava entre 15 e 25 litros. Os animais eram mantidos em sistema semi-intensivo de criação, em pastos formados por capim Brachiaria decunbens ou, Brachiaria brizantha, utilizando-se como volumoso a silagem de milho ou de sorgo, o capim napier e a cana de açúcar, sendo esta dieta complementada pelo fornecimento de farelo de soja, farelo e/ou caroço de algodão, polpa cítrica e cevada. As propriedades visitadas eram 
assistidas por médico veterinário, sendo que a associação do exame físico à análise do histórico permitiu que, na constituição dos grupos experimentais, fossem excluídos animais enfermos ou que apresentavam distúrbios reprodutivos.

Os animais utilizados foram distribuídos segundo a fase do puerpério e pós-puerperal em quatro grupos; conforme a seguir discriminado: Grupo 1- 26 animais sadios no puerpério recente, com até 10 dias após o parto e que não apresentavam distúrbios na evolução do puerpério; Grupo 2 - 28 animais sadios no puerpério tardio, entre 30 e 45 dias após o parto e que não apresentavam distúrbios na evolução do puerpério; Grupo 3- 29 animais sadios na fase pós-puerperal entre 45 e 60 dias após o parto e que não apresentavam distúrbios na evolução do puerpério; Grupo 4 - 21 animais sadios na fase pós-puerperal com mais de 60 dias após o parto e que não apresentavam distúrbio na evolução do puerpério.

As amostras de sangue foram colhidas por punção da veia caudal mediana, utilizando-se o sistema Vacutainer ${ }^{\circledR}$. As amostras de soro sangüíneo utilizadas para a determinação dos teores séricos de colesterol, triglicérides, AGNE e B-HBO foram colhidas em tubos de vidro siliconizados sem anti-coagulante e mantidas em temperatura ambiente para facilitar a retração do coágulo enquanto as amostras de plasma utilizadas para a determinação da glicemia foram colhidas em tubos de vidro siliconizado contendo fluoreto de sódio e mantidas refrigeradas durante o transporte. Nos laboratórios do Centro de Pesquisa de Diagnóstico de Enfermidades de Ruminantes as amostras foram centrifugadas com força real de centrifugação igual a $1000 \mathrm{~g}$, durante 15 minutos, para a ocorrência da sinérese do coágulo ou sedimentação dos elementos figurados do sangue, sendo, a seguir, o soro e o plasma sangüíneos separados por aspiração, e conservados em freezer a menos $20^{\circ} \mathrm{C}$ até a realização das provas.

Os constituintes do lipidograma foram quantificados por metodologia enzimática colorimétrica, em Analisador Bioquímico modelo Liasys - AMS - Itália, utilizando-se kit comercial. As determinações dos teores séricos de colesterol ( utilizando kit comercial da Biosystems ${ }^{\circledR}-\mathrm{N}^{\circ}$ 11505), triglicérides (utilizando kit comercial da Biosystems ${ }^{\circledR}$ - $\mathrm{N}^{\circ}$ 11528), AGNE (utilizando kit comercial da Randox ${ }^{\circledR}$ - No FA 115) e BHBO (utilizando kit comercial da Randox ${ }^{\circledR}$ - $N^{\circ}$ FA 1007) foram realizadas, respectivamente, de acordo com as recomendações de Elphick ${ }^{5}$, Allain et al. ${ }^{6}$, Fossati e Prencipe $^{7}$ e Williamson, Mellanby e $\mathrm{Krebs}^{8}$, enquanto a determinação dos teores plasmáticos de glicose foi realizada utilizando-se kit comercial da marca Diasys ${ }^{\circledR}$ - No 10.250.021 conforme método descrito por Barham e Trinder?.

Para a análise estatística, os resultados foram inicialmente submetidos ao teste de Levene, para testar a hipótese de igualdade de variância. Para as variáveis cujas variâncias foram iguais utilizou-se análise de variância ANOVA para testar a hipótese de igualdade de média entre os grupos. Nos casos em que a hipótese de igualdade de médias foi rejeitada, utilizou-se o teste paramétrico de Bonferroni com nível de $5 \%$ de significância $(p \leq 0,05)$, conforme recomenda Bussab e Morettin10. As variáveis que rejeitaram a hipótese de variâncias iguais no teste de Levene foram submetidas ao teste de normalidade de Kolmogorov-Smirnov para testar a hipótese de distribuição normal das variáveis, nos casos de variáveis que rejeitaram a hipótese de distribuição normal, utilizouse regressões múltiplas, conforme recomenda De Paula ${ }^{11}$.

\section{Resultados}

A análise dos resultados apresentados na tabela 1 evidenciou a influência do puerpério nos teores séricos de colesterol, sendo os valores mínimos desta variável $(67,72 \pm 17,77 \mathrm{mg} / \mathrm{dL})$ observado em amostras colhidas de animais no puerpério recente (menos de dez dias após o parto). Com a evolução do puerpério os teores 
Tabela 1 - Média, desvio padrão e amplitude de variação dos teores séricos de colesterol, triglicérides, ácidos graxos não esterificados (AGNE), beta-hidroxibutirato e teores plasmáticos de glicose, de fêmeas bovinas da raça Holandesa criadas no Estado de São Paulo distribuídas segundo a fase do puerpério São Paulo - 2006

\begin{tabular}{|c|c|c|c|c|c|c|}
\hline Fase do Puerpério & $\mathrm{N}$ & $\begin{array}{l}\text { Colesterol**** } \\
\qquad(\mathrm{mg} / \mathrm{dl})\end{array}$ & $\begin{array}{l}\text { Triglicérides**** } \\
\text { (mg/dl) }\end{array}$ & $\begin{array}{l}\text { AGNE* } \\
(\mu \mathrm{mol} / 1)\end{array}$ & $\begin{array}{c}\text { Beta- } \\
\text { hidroxibutirato.* } \\
(\mathrm{mg} / \mathrm{dl})\end{array}$ & $\begin{array}{l}\text { Glicose**** } \\
\text { (mg/dl) }\end{array}$ \\
\hline $\begin{array}{c}\text { Puerpério Recente } \\
\text { (0 a } 10 \text { dias após o parto) }\end{array}$ & 26 & $\begin{array}{l}67,72 \pm 17,77 a \\
(31,0-109,9)\end{array}$ & $\begin{array}{c}17,82 \pm 5,38 \mathrm{a} \\
(5,0-30,2)\end{array}$ & $\begin{array}{c}720,68 \pm 411,48 \mathrm{a} \\
(264,57-2076,30)\end{array}$ & $\begin{array}{c}5,84 \pm 2,37 \mathrm{a} \\
(2,82-12,76)\end{array}$ & $\begin{array}{l}53,20 \pm 9,44 a \\
(18,0-65,0)\end{array}$ \\
\hline $\begin{array}{c}\text { Puerpério Tardio } \\
\text { (30 a } 45 \text { dias após o parto) }\end{array}$ & 28 & $\begin{array}{l}133,92 \pm 34,40 \mathrm{~b} \\
(82,8-220,6)\end{array}$ & $\begin{array}{c}22,25 \pm 15,66 \mathrm{a} \\
(10,3-97,7)\end{array}$ & $\begin{array}{l}474,75 \pm 299,40 \mathrm{ab} \\
(67,55-1096,80)\end{array}$ & $\begin{array}{c}5,07 \pm 2,23 \mathrm{a} \\
(2,49-14,15)\end{array}$ & $\begin{array}{l}58,76 \pm 9,86 a \\
(39,0-77,0)\end{array}$ \\
\hline $\begin{array}{c}\text { Fase pós-puerperal } \\
\text { (45 a } 60 \text { dias após o parto) }\end{array}$ & 29 & $\begin{array}{l}180,22 \pm 44,97 \mathrm{c} \\
(103,6-264,5)\end{array}$ & $\begin{array}{c}10,59 \pm 7,89 \mathrm{~b} \\
(0,4-28,6)\end{array}$ & $\begin{array}{c}314,65 \pm 313,82 \mathrm{~b} \\
(48,04-1650,50)\end{array}$ & $\begin{array}{l}4,78 \pm 1,53 \mathrm{a} \\
(2,43-8,26)\end{array}$ & $\begin{array}{l}54,35 \pm 5,28 \mathrm{a} \\
(41,0-67,0)\end{array}$ \\
\hline $\begin{array}{c}\text { Fase pós-puerperal } \\
\text { (> } 60 \text { dias após o parto) }\end{array}$ & 21 & $\begin{array}{c}179,67 \pm 54,40 \mathrm{c} \\
(87,6-268,1)\end{array}$ & $\begin{array}{c}17,05 \pm 5,86 \mathrm{a} \\
(4,1-29,8)\end{array}$ & $\begin{array}{c}286,05 \pm 358,65 b \\
(29,31-1705,80)\end{array}$ & $\begin{array}{c}5,56 \pm 1,33 \text { a } \\
(3,43-9,24)\end{array}$ & $\begin{array}{l}54,85 \pm 5,81 \mathrm{a} \\
(44,0-63,0)\end{array}$ \\
\hline
\end{tabular}

$a, b, c$ letras diferentes na mesma coluna, denotam presença de diferença estatística significante.

* Teste paramétrico de Bonferroni $(\mathrm{p} \leq 0,05)$

***** Teste de regressão $(\mathrm{p} \leq 0,05)$

séricos de colesterol aumentaram gradativamente até atingirem, no grupo composto por animais em fase póspuerperal (entre 45 e 60 dias após o parto), valores médios iguais a $180,22 \pm 44,97 \mathrm{mg} /$ dL. A partir desse momento, os teores de colesterol passaram a oscilar sem que diferenças estatísticas pudessem ser observadas.

Verificou-se que o puerpério influenciou os teores séricos de triglicérides (Tabela 1), pois os valores encontrados no grupo composto por animais na fase pós puerperal, entre 45 e 60 dias pós parto $(10,59 \pm 7,89 \mathrm{mg} / \mathrm{dL})$ foram menores do que aqueles observados no grupo de animais no puerpério recente $(17,82 \pm 5,38 \mathrm{mg} / \mathrm{dL})$, puerpério tardio $(22,25 \pm 15,66 \mathrm{mg} / \mathrm{dL})$ e fase pós-puerperal com mais de 60 dias após o parto $(17,05 \pm 5,86 \mathrm{mg} / \mathrm{dL})$.

Com relação aos teores séricos de ácidos graxos não esterificados (AGNE) verificou-se a influência do puerpério fisiológico, sendo os valores máximos desta variável $\quad(720,68 \pm 411,48 \mathrm{mmol} / \mathrm{L})$ observados em amostras colhidas de animais no puerpério recente (menos de dez dias após o parto). Com o evoluir do puerpério observou-se gradual diminuição dos teores séricos de ácidos graxos não esterificados até atingirem, no grupo composto por animais em fase pós-puerperal (entre 45 e 60 dias após o parto), valores médios iguais a $314,65 \pm 313,82 \mathrm{mmol} / \mathrm{L}$. A partir deste momento existia a tendência dos valores se estabilizarem.

Ao avaliar a influência do puerpério e da fase pós-puerperal nos teores séricos de beta-hidroxibutirato (Tabela 1) não foram encontradas diferenças entre os pares de médias, sendo que os seus valores oscilaram, nos diversos grupos experimentais, entre $4,78 \pm 1,53 \mathrm{mg} / \mathrm{dl} \mathrm{e} 5,84 \pm 2,37 \mathrm{mg} / \mathrm{dl}$.

A análise dos resultados apresentados na tabela 1 mostra que a glicemia não foi influenciada pelo puerpério, sendo que nos diversos grupos experimentais os seus teores

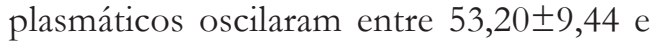
$58,76 \pm 9,86 \mathrm{mg} / \mathrm{dL}$.

\section{Discussão}

Relativo à influência do puerpério e da fase pós-puerperal no lipidograma observou-se que os teores séricos de colesterol aumentaram gradativamente com a evolução do puerpério ${ }^{1,12}$, sendo relato por Bronicki e Dembinski ${ }^{13}$ que esse aumento seria precedido de diminuição dos seus valores nas primeiras duas semanas após o parto. Sobre o momento em que os teores séricos de colesterol retornariam aos patamares observados na fase inicial da gestação constatou-se a existência de poucas referências na literatura compulsada. Pelos resultados apresentados nesta pesquisa esse 
retorno ocorreu a partir do $45^{\circ}$ dia pósparto, enquanto para Bronicki e Dembinski ${ }^{13}$ esse retorno ocorreria na $8^{\mathrm{a}}$ semana após o parto e para Kappel et al. ${ }^{12}$ aproximadamente 90 dias após o parto.

Apesar dos teores séricos de ácidos graxos não esterificados serem maiores no puerpério do que os observados nos dois primeiros terços da gestação ou na fase pós-puerperal 1,13,14,15,16, não houve unanimidade entre os pesquisadores no comportamento desta variável, pois algumas pesquisas ${ }^{14,16}$ indicavam, a semelhança dos resultados apresentados na presente pesquisa, diminuição gradual durante todo o puerpério. Outras pesquisas verificaram que nos primeiros 30 dias após parto ocorria aumento dos valores séricos de ácidos graxos não esterificados ${ }^{1,15}$ ou, ainda, que esse aumento já era percetível nas últimas quatro semanas antes do parto que e perdurava até a oitava semana após o parto ${ }^{13}$.

Observou-se que os teores séricos de triglicérides observados no grupo composto por animais entre 45 e 60 dias pós parto eram estatisticamente menores do que o observado para o grupo de animais no puerpério recente, puerpério tardio e com mais de 60 dias após o parto. Apesar da literatura compulsada afirmar que os teores séricos de triglicérides eram menores durante o puerpério ${ }^{1,13,17}$, considerou-se que os resultados obtidos na presente pesquisa não permitiam avaliação fidedigna da natureza da influência do puerpério nos seus valores.

Os resultados obtidos nesta pesquisa refletem as alterações esperadas para o lipidograma de animais em balanço energético negativo, situação essa que sabidamente ocorre na fase final da gestação e no puerpério. $\mathrm{O}$ aumento dos teores séricos de ácidos graxos não esterificados (AGNE) é conseqüência da hidrólise dos triglicérides do tecido adiposo, sendo que parte desse ácido graxo não esterificado, ao atingir o fígado é utilizado para a produção de triglicérides ${ }^{1,14,18}$. Da mesma forma, a diminuição dos teores séricos de colesterol encontrados nesta pesquisa durante o puerpério dos bovinos reflete alterações no metabolismo do fígado, com redução da síntese do colesterol, em decorrência a um quadro de esteatose hepática ${ }^{19,20}$. Em virtude da velocidade de formação dos triglicérides hepáticos exceder a capacidade de liberação deste triglicéride para o plasma ocorre, na fase final da gestação e no puerpério, a deposição de triglicérides nos hepatócitos, instalando-se com acúmulo de gordura no fígado uma esteatose hepática ${ }^{18}$.

Verificou-se, também, que nos animais com puerpério fisiológico, apesar da intensa mobilização de gordura corpórea e a ocorrência de esteatose hepática, não há aumento na produção de corpos cetônicos, uma vez que os teores de beta-hidroxbutirato não sofreram variações durante o período avaliado, indicando que havia quantidade suficiente de oxaloacetato para a produção de energia $^{21}$.

Ao fazer-se a comparação dos teores séricos de colesterol, ácidos graxos não esterificado,triglicérides, betahidroxibutirato e os teores plasmáticos de glicose encontrados para a fase póspuerperal com aqueles referidos na literatura brasileira, ${ }^{1,2,3,4}$ verificou-se que os mesmos encontravam-se dentro da amplitude de variação considerada como fisiológica. Entretanto, evidenciou-se que, durante o puerpério recente e tardio, a magnitude da diferença observada para os teores séricos de colesterol e ácidos graxos não esterificado era muito grande. Este fato justifica e torna recomendável que nos primeiro 45 após o parto sejam adotados valores de referência específicos para essas duas variáveis (colesterol e ácidos graxos não esterificado), permitindo a correta interpretação dos resultados obtidos para o metabolismo lipídico dos bovinos.

\section{Conclusão}

O puerpério influenciou o lipidograma de vacas holandesas sadias, sendo verificado 
que os teores séricos de colesterol aumentaram gradativamente, enquanto os teores de ácidos graxos não esterificados diminuíram gradativamente com a evolução do puerpério. $\mathrm{Na}$ fase pós-puerperal (mais de 45 dias pós-parto) ocorreu a estabilização dos valores de colesterol e de ácidos graxos não esterificados.

\section{Agradecimentos}

À Fundação de Amparo à Pesquisa do Estado de São Paulo (processo no 03/ 00031-1) pelo financiamento da pesquisa.

\section{Influence of puerperium and post-puerperal phase on the lipid profile of health Holstein cows}

\section{Abstract}

Aiming to assess the influence of physiological puerperium and postpuerperal phase on the lipid profile of health cows 104 blood samples were collected by coccygeal vein puncture of Holstein cows raised in the State of São Paulo. Lipid profile assessment was measured by serum levels of cholesterol, triglycerides, nonesterified fatty acids, âhydroxybutyrate and plasma glucose level. With regard to puerperium and post-puerperal phase influence on the lipid profile, gradual increase of serum cholesterol level and decrease of nonesterified fatty acids were observed with puerperal evolution. The values of cholesterol and nonsterified fatty acids were stabilized during post-puerperal phase (greater than 45 day postparturm).

\section{Referências}

1 COSTA, S. G. Perfil lipídico de vacas Holandesas, variedade HPB, em diferentes fases da gestação. 1991. 57 f. Dissertação (Mestrado) - Faculdade de Medicina Veterinária e Zootecnia, Universidade de São Paulo, São Paulo, 1991.

2 BORGES, A. M.; TORRES, C. A. A.; RUAS, J. R. M.; CARVALHO, G. R.; ROCHA JÚNIOR, V. R. Concentração plasmática de colesterol total e lipoproteína de alta densidade em novilhas mestiças doadoras de embriões tratadas com somatotropina bovina recombinante. Arquivo Brasileiro de Medicina Veterinária e Zootecnia, v. 53, n. 5, p. 205-210, 2001.

3 RENNÓ NETO, B. P. Influência da aplicação da somatotropina recombinante bovina na função hepática, renal e lipidograma de bovinos da raça holandesa em lactação. 2004. 116 f. Dissertação (Mestrado), Faculdade de Medicina Veterinária e Zootecnia, Universidade de São Paulo, São Paulo, 2004.

4 SUCUPIRA, M. C. A. Estudo comparativo de exames clínico-laboratoriais no diagnóstico de carência energética prolongada em garrotes. 2003. $173 \mathrm{f}$. Tese (Doutorado) - Faculdade de Medicina Veterinária e Zootecnia, Universidade de São Paulo, São Paulo, 2003.

5 ELPHICK, M. C. Modified colorimetric ultramicro
Key words:

Bovine.

Lipid profile.

Puerperium.

Holstein. method for estimating NEFA in serum. Journal of Clinical Pathology, v. 21, n. 5, p. 567-570, 1968.

6 ALLAIN, C. C.; POON, L. S.; CHAN, C. S. G.; RICHMOND, W.; FU, P. C. Enzymatic determination of total serum cholesterol. Clinical Cheminstry, v. 20, n. 4, p. 470-475, 1974.

7 FOSSATI, P.; PRENCIPE, L. Serum triglycerides determined colorimetrically with na enzyme that produces hydrogen peroxide. Clinical Chemistry, v. 28, n. 10 , p. 2077-2080, 1982

8 WILLIAMSON, D. H.; MELLANBY, J.; KREBS, H. A. Enzymatic determination of $\mathrm{D}(-)$ ß-hydroxybutyric acid and acetoacetic acid in blood. Biochemical Journal, $\mathrm{v}$. 82, pt. 1, p. 90-96, 1962.

9 BARHAM, D.; TRINDER, P. An improved color reagent for the determination of blood glucose by oxidase system. Analyst, v. 97, n. 1151, p. 142-145, 1972.

10 BUSSAB, W. O.; MORETTIN, P. A. Estatística básica. 4. ed. São Paulo: Atual, 1986. 329 p.

11 DE PAULA, G. A. Modelos de regressão: com apoio computacional. São Paulo: IME-USP, 2004. 245 p.

12 KAPPEL, L. C.; INGRAHAM, R. H.; MORGAN, E. B.; ZERINGUE, L.; WILSON, D.; BABCOCK, D. K.; STAT, M. A. Relationship between fertility and blood glucose and cholesterol concentrations in Holstein cows. American Journal of Veterinary Research, v. 45, 
n. 12 , p. 2607-2612, 1984.

13 BRONICKI, M.; DEMBINSKI, Z. Evaluation of the post-natal fertility in dairy cows with lipid metabolism disturbances at various intensities. Bulletin of the Veterinary Institute in Pulawy, v. 39, n. 1, p. 39-42, 1995.

14 CHRISTIE, W. W. Lipid metabolism in ruminant animals. Oxford: Pergamon Press, 1981. 452 p.

15 GRIMOLDI, R. J.; MARQUESZ, A. H.; TIRANTE, H.; RUTTER, B.; CORUNJEIRA, M. CASAL, G. Effects of partum and lactation blood lipids in holandoargentine cows: the future In: BLACKMORE, D. J. (Ed.) Animal clinical biochemistry. Cambridge: Cambridge University Press, 1988. p. 292-296. Paper presented at the IIIrd International Meeting of the Society of Anima Clinical Biochemistry.

16 RADLOFF, H. D.; SCHULTZ, L. H.; HOEKSTRA, W. G. Relationship of plasma free fatty acids to other blood components under various physiological conditions. Journal of Dairy Science, v. 49, n. 2, p.
179-182, 1966

17 MARQUES JUNIOR, A. P.; CASTILLO CASTILLO, O. A. Glicose e triglicérides plasmáticos de vacas holandesas próximo ao parto e no puerpério. Arquivo Brasileiro de Medicina Veterinária e Zootecnia, v. 48, n. 3, p. 309-315, 1996.

18 BRUSS, M. L. Lipids and ketones. In: KANEKO, J. I. (Ed.). Clinical biochemistry of domestic animals $5^{\text {th }} \mathrm{ed}$. San Diego: Academic Press, 1997. p. 83-115.

19 BOBE, G.; AMETAJ, B. N.; YOUNG, J. W.; BEITZ, D. C. Effects of exogenous glucagon on lipids in lipoproteins and liver of lactating dairy cows. Journal of Dairy Science, v. 86, n. 9, p. 2895-2903, 2003.

20 NOBLE, R. C. Digestion, absortion and transport lipids in ruminants. In: CHRISTIE, W. W. (Ed.). Lipid metabolism in ruminants animals. Oxford: Pergamon Press, 1981. p. 57-93.

21 BEITZ, D. C. Dukes fisiologia dos animais domésticos. 11. ed. Rio de Janeiro: Guanabara Koogan, 1996. 856 p. 